\title{
Perspectives on literacy: Exploring functional vs. sociocultural views on adult literacy learning in the case of Uganda
}

\author{
Sarah Hasaba
}

\begin{abstract}
Illiteracy remains a global concern, especially among developing countries like Uganda. The 1990 World Education Conference in Jomtien, Thailand drew attention to the increasing number of illiterate individuals in the world, especially in developing countries. Consequently, the Education For All (EFA) campaign was launched, with UNESCO spearheading it. The campaign urged both developed and developing countries to invest in improving literacy and education levels among children and adults. The support for universal primary education has been enormous, with the United Nations putting forward eight Millennium Development Goals in 2000 to be achieved by 2015; goal 2 emphasizes universal primary education. This paper explores adult literacy promotion as an EFA effort and presents UNESCO's drive for functional literacy. It also presents the Ugandan government's Functional Adult Literacy Program and juxtaposes it against other alternative approaches to literacy learning, such as the social and sociocultural views of literacy. Findings from research conducted in 2006 and 2011 on the Functional Adult Literacy Program in Uganda not only point to program challenges limiting its effectiveness, but also call for a social approach to implementing any adult literacy program.
\end{abstract}

\section{Introduction}

Illiteracy remains a global concern because of its effect on socioeconomic development among individuals in developing countries like Uganda. The 1990 World Education Conference in Jomtien, Thailand drew attention to the increasing number of illiterate individuals in the world, especially in developing countries. Consequently, the Education For All (EFA) campaign was launched, and had the United Nations Education, Science and Cultural Organization (UNESCO) spearheading it by calling upon both developed and developing countries to invest in the fight against illiteracy among children and adults. UNESCO's global statistics reveal that one in five adults is illiterate and that "literacy remains among the most neglected of all education goals, with about 759 million adults lacking literacy skills, a majority of whom are women and in sub-Saharan Africa" (UNESCO, 2010, p. 4). Furthermore, UNESCO supports the view that "literacy opens doors for better livelihoods, improved health and expanded opportunity" (UNESCO, 2011, p. 65).

This paper explores adult literacy promotion efforts as part of the broad Education For All campaign and presents UNESCO's drive for the functional version to literacy. It also discusses the Ugandan government's Functional Adult Literacy (FAL) Program and juxtaposes it against other alternative approaches to literacy learning such as the social and 
sociocultural views of literacy. Qualitative research data collected from among Functional Adult Literacy Program learners in 2006 and 2011 will further inform this discussion.

\section{The Functional View of Literacy}

At its simplest level, literacy has been defined as the ability to read and write and spell correctly (Blake \& Blake, 2002, p.13; Okech, 2004, p. 178). Alphabetic subskills as well as functional views of literacy are built upon this base, commonly assuming a linear progression from simple to more complex functionally relevant skills. However, as Jeffrey \& Maginn (1979) argue, to "confine the definition of literacy to merely the ability to read and write implies a narrowest possible view of looking at literacy" (cited in Hamilton, Barton \& Ivanic, 1994, p. 107). Street (1984) refers to the two models (autonomous and ideological) in his definition and understanding of literacy. All literacy is ideologically constructed, although individuals choose to set standards and limitations about what comprises literacy and who is literate/illiterate. The autonomous model is a "division between literate and nonliterate and it is not discriminative between cultures but simply between technologies" (p. 29). It supposedly involves neutral and context-free technologies.

The functional view of literacy falls under the autonomous model. It was developed in the 1950s and 1960s. It is skills based, tending to focus on the deficiencies that exist in society and the need to respond to particular deficiencies with skills training. Gray (1956), for instance, wrote about functional literacy as "someone being functionally literate if they are able to engage effectively in all those activities in which literacy is normally assumed in [their] culture or group" (p. 24). UNESCO (1970) advanced this concept of literacy as that which aids "humans in the performance of their functions ... most important of which is that of being a producer" (p. 27).

Literacy under the functional view is considered a tool and/or a measure of performance and competency, and individuals are assessed as either competent or incompetent as a result of engaging in this kind of literacy. This kind of literacy advanced by UNESCO paid attention to the mechanical aspect of functional literacy, where having skills and updating them were a prerequisite for active adult participation in individual communities. A mechanical view of literacy lacks the understanding of individuals within sociocultural contexts. These conflicting views of functional literacy led UNESCO to reinvent their version of literacy. During a "UNESCO conference in Tehran in 1965, functional literacy was tied directly and tightly to economic functions" (Bhola, 1994, p. 32). However, even with reinvention of functional literacy by UNESCO, there were still questions surrounding the idea of functional literacy. In particular, there was a failure in a functional literacy viewpoint to recognize the importance that cultural settings played in the way individuals responded to literacy provision.

In the years between 1967 and 1974, UNESCO organized an Experimental World Literacy Program (EWLP). Gillette (1987) writes about this worldwide UNESCO approach to literacy as "an unprecedented, and remained in educational history an unequalled, multilateral literacy venture in terms of international resources mobilized, political and technical interest aroused, and controversy unleashed" (p. 197). UNESCO attempted to develop one approach to literacy provision that involved the world as one big classroom where testing and demonstration of assumed literacy training was to take place. This same 
concept is used in Uganda whereby the government is pushing for a national adult literacy program for its own sake, without reflecting on the would-be deep-rooted social impact on individuals and how they choose to use and sustain the acquired literacy skills within their local communities. Uganda's Functional Literacy Program is discussed in the next section.

\section{The Government's Provision of Functional Adult Literacy (FAL) in Uganda}

The Government's FAL Program has its roots in the functional version of literacy introduced and promoted by UNESCO. UNESCO played a big role in the reintroduction of Uganda's Functional Adult Literacy Program, including through a "number of planning workshops held in 1983, 1987 and 1989, co-financed by the Government of Uganda and UNESCO" (Okech, Carr-Hill, Katahoire, Kakooza \& Ndidde, 1999, p. 12). The government's Ministry of Gender, Labour and Social Development (MGLSD) is responsible for the FAL Program and defends this view of literacy as vital in improving learners' lives:

A participatory approach that would motivate learners to continue searching for knowledge and skills that would help them to improve on whatever activities they were engaged in for the betterment of their lives and the communities where they lived. (MGLSD, 2001, pp 1-2).

This literacy discourse places emphasis on individuals obtaining skills that would enable them to actively improve their lives. It is also worth mentioning that the implementation of the FAL Program as an informal program began in 1992 following a pilot adult literacy project in eight districts of Uganda-Apac, Hoima, Kabarole, Mpigi, Mbarara, Mukono, Iganga and Kamuli-in the same year. This adult literacy project was known as the Integrated Nonformal Basic Education Pilot Project (Infobepp). The October 1995 Process Review of this pilot project by an international team of experts revealed in the form of conclusions and recommendations the "very strong demand" as well as the need for a "decentralized" program approach:

There was an overwhelming demand for adult literacy at all levels evidenced by the fact that there were almost as many literacy classes outside the pilot project areas which had sprang up because of the strong demand for literacy as a result of the raised awareness and expectations ...

There should be a decentralized program structure that complements the political process with clear definition of roles of the centre and the districts. (Okech et al., 1999, pp. 15-16)

The government's response to the overwhelming demand started with a name change of the literacy program from Integrated Nonformal Basic Education Pilot Project (Infobepp) to the National Functional Adult Literacy Program (Okech et al., 1999, p. 7). Then adult literacy became part of a poverty reduction strategy that is supported by the International Monetary Fund (IMF). The World Bank's “1995 paper on strategies for education, acknowledged the problem of illiteracy among the poorest people of the poorest countries and the need to provide the kinds of education that would work to reduce their poverty" (Carr-Hill, Okech, Katahoire, Kakooza, Ndidde \& Oxenham, 2001, p. xi). 
Although the World Bank analysis does not specifically mention adult literacy learning, I think that some of the underlying challenges to socioeconomic development involve lack of education and literacy skills. So the FAL Program, linked to economic skills and poverty reduction efforts, ensured that Uganda would continue implementing the UNESCO version of literacy; a version central to understanding and implementing the IMF/World Bank's structural adjustment policies (SAPs) that promised the improvement of people's socioeconomic situations in developing countries.

The Government of Uganda continues to acknowledge the presence of and challenges posed by adult illiteracy in the country (MGLSD, 2003a). The current adult literacy level for individuals aged 15 years and above stands at 73 percent (Uganda Population Secretariat, 2011). Therefore, the FAL Program as a national literacy program with potential for country-wide coverage is implemented under three levels of Ministry, District and Subcounty. Some of the roles of the Ministry include policy formulation and development, and program design, development and implementation, as well as networking with other actors in the area of adult literacy (MGLSD, 2001, p. 4). At the District and Subcounty levels, the FAL Program falls under the Department of CommunityBased Services. A District Community Development Officer (DCDO) and Subcounty Community Development Officer (SCDO) are appointed to oversee activities within the District and Subcounty. The Department of Community-Based Services is comprised of six sectors: (i) Child Care, (ii) Youth (iii) Culture, (iv) Gender and Women in Development, (v) The Disabled and Elderly, and (vi) Labour.

\section{Stages within the FAL Program}

The FAL Program has three stages. Stage one is the beginners' stage where adult learners receive 180-226 contact hours with the literacy instructor and is equivalent to nine months of study. Stage two is another nine months with the same contact hours as stage one. Stage three, introduced in 2006, has 150-180 contact hours between adult learners and their literacy instructor. However, not many literacy instructors have enrolled learners in this stage. Upon completion of each stage, learners are required to take a proficiency test, which determines whether or not they can proceed to the next stage. The government program stipulates that learners are to have six contact hours per week.

It is envisaged that upon successful completion of the three stages in the FAL Program, adult learners' competency will be equivalent to the primary four level of formal schooling in Uganda. The same goal was put forward by Ngatjizeko (2005) with respect to adult learners participating in Namibia's national literacy program.

\section{Language(s) of Instruction}

Given that the FAL Program addresses adult literacy as a community development effort, instruction in the literacy class is in the local language of the community. Uganda has many different tribes so learners are expected to be familiar with the local language. Across Uganda, the seven languages used for instruction under the FAL Program are Luganda, Luo, Lunyankole, Lukiga, Lutoro, Ateso, and Lukonjo. This selection, based on the large numbers of people speaking these languages, has not been contested in the FAL Program. Ladefoged, Glick \& Criper (1971), writing on language in Uganda, mention that "language has to serve 
as a mother tongue or first language to at least 55 percent of the population" (cited in CarrHill et al., 2001, p. 6). The mother tongue is used in the community and at home.

Also, some of these languages used in the FAL Program are media languages in that there are newspapers published and radio programs aired in them. However, English remains the official and business language in Uganda, and stage three of the FAL Program aims to teach adult learners functional English, even though the learners continue learning in the local language.

\section{The FAL Program Curriculum}

The printed 2003 copy of the FAL curriculum, designed and developed with the assistance of experts, focuses on such areas as "health, legal issues, agriculture, cooperative and marketing, animal husbandry, gender issues, culture and civic consciousness as well as language" (MGLSD, 2003b, p. 3). As a government document, the Ministry proposes that the FAL curriculum

presents the learner with an opportunity for learning through problem solving for sustainable self and community development. It also encourages the learner to develop positive attitudes towards learning and work through practical activities. (MGLSD, 2003b, p. 4)

However, a Process Review conducted between 2002-2006 on the FAL Program recommended some of the following:

The revision of the FAL curriculum and materials for more relevance to learners' needs and the poverty eradication efforts; develop links between literacy learning and practice so as to promote beneficial literacy use in the home and the community and at work. (MGLSD, 2008, p. 63)

This is the second process review on the FAL Program since its inception in 1992. The quality of the literacy program and its relevance to learners in their everyday life is significant.

\section{The Literacy Instructors}

Literacy instructors are volunteers from the wider community who enroll in an "initial training in adult literacy methods that lasts ten days and is usually followed by a one-day follow-up training" (Kisira, 2005, p. 67). Although both men and women are encouraged to volunteer as instructors, most literacy instructors are men, as are the literacy implementers. Socioeconomic and sociocultural factors still marginalize women and restrict their mobility and time. Those who go on to become literacy instructors receive at the end of the training an instructor's manual, literacy primers for the learners, a blackboard, and chalk. In some instances, literacy instructors-usually males-receive logistical support in the form of bicycles to facilitate their work in their community. There is no financial remuneration for literacy instructors. 
Through talking to some of the FAL instructors during both the 2006 and 2011 fieldwork research activities, I found out that most taught the first two stages of the program. The quality of FAL instructors in the literacy program and the length of training they undergo are criticized. Kisira (2005), of the Literacy and Adult Basic Education (LABE) ${ }^{1}$ organization in Uganda, writes that "technical support to instructors, in terms of supervision, is inadequate. It is therefore of no surprise that the quality of adult literacy provision is generally very poor" (p. 67). The credibility of the FAL Program is therefore questionable, as it appears that little attention is being paid to the quality of the literacy service on offer.

\section{Beyond a Functional Understanding of Literacy}

There are many other schools of thought, besides the functional understanding of literacy, that have emerged and that define and understand literacy from a social or sociocultural viewpoint. The discussion in this section focuses on the social/ideological view of literacy as well as the sociocultural view of literacy.

\section{Social/Ideological View of Literacy}

The ideological model emphasizes literacy around values and contexts. Street (1984, p. 96; 1993, p. 7) asserts that "there are multiple literacies that exist and that the meanings and uses of literacy practices are specific to cultural contexts." He argues further for the "cognitive aspects of reading and writing to be understood within cultural wholes and also within structures of power" (Street, 1984, p. 96). Street emphasizes a social positioning of literacy learning. Within the structures of power and the FAL Program implementation at the Subcounty level, there are parishes and villages. The FAL classes are held at the village level, which administratively in Uganda is the lowest level, while the central government under which the Ministry of Gender, Labour and Social Development falls is the highest level. Literacy classes held at the village level are meant to enable adult learners to access them. Adult learners are in fact encouraged to select venues for learning as a way of involving them in the literacy program.

The social/ideological view recognizes the various dimensions of literacy learning. Grant (1987) writes that "literacy involves the four dimensions of language use; reading, writing, speaking, and listening, together with thinking which is integral throughout" (p. 11). Also, the acceptance of varying definitions of the term literacy indicates the flexibility in concept. Mace (1992) notes that "meanings and uses of literacy and equality have shifted with different social and historical contexts" (p. 141). Literacy is not simply about learning to read and write one's name or identify numerical values, as is often the case in the FAL classes and is also a notion held by most first-time adult learners. Rather, literacy is a relative concept associated with specific contexts, places, and times. Although functional skills-based views assume that literacy moves from basic to advanced levels, this is problematic, as there is no universal meaning, definition, or understanding attributed to the term. Grant (1987) writes that "literacy is ... not the attainment of a particular level of

\footnotetext{
${ }^{1}$ LABE is an indigenous, national-level adult literacy training NGO that focuses on literacy, operates a literacy resource organization, offering literacy management, training of trainers and literacy instructors, consultancy and materials development for NGOs, CBOs and government departments.
} 
mastery" (p. 11). Wickert (1989) also defines literacy as "a 'moving target' which evolves and changes as individuals and communities constantly redefine what it means to be literate" (cited in Macdonald, 1993, p. 7). The definition and understanding of literacy extends beyond just developing reading and writing skills.

Literacy can be remodeled to meet the changing needs of the learners. For example, in the 2011 research data used in this discussion, learners that were interviewed expressed a desire to be computer literate, an issue that is not included in the FAL Program curriculum. This desire is an indication of the changes in learning needs of the learners and the fact that they feel inclined to take charge of their own learning in order to make it more relevant for them. Chlebowska (1990) refers to "literacy as a factor of personal enrichment and at the very least a right to which everyone must have access" (p. 53). The success of literacy uses depends on how people interconnect literacy with their everyday life in order to be fulfilled. By contrast, if there are disconnections between literacy learning and the experiences in learners' lives, it is impossible for them to discuss the personal as well as social and sociocultural benefits of literacy.

\section{Literacy Events and Literacy Practices}

The social/ideological view appreciates the role of literacy events and practices. Literacy develops through events and practices. Heath (1983) refers to a literacy event as an occasion where "writing is integral to the nature of ... interactions and ... interpretations of meaning. Reading is a social activity that almost always provokes narratives, jokes, sidetracking talk, and active negotiation of the meaning of written text" (p. 200). In a literacy event, literacy is not a set of skills but an occasion in which individuals make meaning with written text. The cognitive skills that people bring to a literacy event and the associated practices they develop influence the meanings they make of their experiences. Adult learners are often encouraged to share their wealth of experience in literacy classes so as to make learning an enjoyable activity.

Literacy practices, on the other hand, form part of everyday life and understandings of literacy. Barton (1994) explains literacy practices as "general cultural ways of using reading and writing which people draw upon in a literacy event" (p. viii). Street (1995) discusses the role of social interactions in literacy learning, asserting that "literacy itself varies with social context" (p. 53). The value is in the ordinary resources that learners draw upon to motivate their learning. Community activities such as village meetings, religious services, political gatherings, or visiting the local health unit provide opportunities for individuals to encounter literacy activities and be part of them.

Furthermore, Street (1996) writes that literacy practices as part of people's lives "remain social and cultural practices, which are related to people's cultural identity, their sense of self, their knowledge and world view" (p. 8). Literacy practices provide individuals with a link to the wider community through the new and varied information they encounter. People differ in their experiences of the world, and use their cultural constructions to better understand their world. Therefore, literacy has to be continuous to allow individuals to progress beyond the basic level to more advanced levels of understanding that allow them to compose meaning in their participation within literacy discourses. One observation noted from the learners interviewed in the 2011 research 
study is that many of them who are in the post-literacy stage stayed on in the literacy classes for as long as possible. This is because the literacy classes are events that allow them to fully participate and in turn sustain their acquired literacy skills.

\section{Literacy: An Inseparable Entity from Everyday Life}

Literacy means many different things according to time, values, place, viewpoints, and contexts-so much so that the terms literacies and multiliteracies have become commonplace. Literacy does not have to be imposed in terms of when and what skills an individual should possess in order to fit into society. Different societies have different constructions of literacy. "Literacy is taken to mean an educated state that can be achieved through the exercise of literate skills" (Levine, 1986, p. 22); Taylor \& Dorsey-Gaines (1988,) assert that literacy cannot mean "a discrete event, nor a package of predetermined skills" (p. 201), as was the case with the UNESCO version of functional literacy.

Furthermore, it is necessary to take into account that literacy is "associated with various implications and discourses" (Christie, 1990, p. 2). Discussions about the meaning of literacy go beyond literacy being skills based, especially given newly emerging domains of literacy "such as computer literacy, workplace literacy, functional literacy, family literacy, and critical literacy" (Suda, 2001, p. 1). Barton (2007) explains, "it is important in making central the idea that literacy is a relative matter, relative to a particular society or group" (p. 190). This makes clear that there can be no claims to universal literacy, as the meaning, definition, and understanding of literacy involves articulation, and the realization that to be literate is an individual journey and a lifelong investment with coherence and progression. Literacy learning, according to Grant (1987), involves "the whole person and is inseparable from the way we live our lives" (p. 9). Indeed, in "a literate society, reading and writing are used for real communicative purposes" (Luke, 1988, p. 9). Heath (1983) notes that in "any literacy activity, there is an opportunity to use reading and writing for different purposes" (pp. 258-259). Taylor (1997) outlines some of these different purposes of reading and writing: "reading can take the form of conformational, educational, environmental, financial use and writing can be for autobiographical, creative, educational, environmental purposes etc." (pp. 181-182).

Essentially, literacy can be about an individual's history, capability, and possibilities, as well as about the four roles of code breaking meaning making, text usage in social contexts. and text analysis (Luke \& Freebody, 1999):

Breaking the code of text: where as a learner, recognizing and using the fundamental features and architecture of written texts include: alphabet, sounds in words, spelling, conventions and patterns of sentence structure and text.

Participating in the meanings of texts: understanding and composing meaningful written, visual and spoken texts from within the meaning systems of particular cultures, institutions, families, communities, nations and so forth.

Using texts functionally: traversing the social relations around texts; knowing about and acting on the different cultural and social functions that various texts perform both inside and outside school and knowing that these functions shape the way 
texts are structured, their tone, their degree of formality and their sequence of components.

Critically analyzing and transforming texts: understanding and acting on the knowledge that texts are not neutral, that they represent particular views and silence other points of view, influence people's ideas. (pp. 6-7)

Successful literacy learning requires these four roles, which are integrated in a successful reading activity. I doubt if the training that the literacy instructors undergo equips them with the ability to guide the learners to integrate the four roles in such a way that they both decode and encode- "reading the word and the world" (Freire and Macedo, 1987), and relating written language to the realities of their lives.

The meaning-making role is vital for learners in the FAL classes if they are to connect literacy learning with growth and development in their communities. In the role of text user, learning is about the kind of text used in the world and recognizing its importance. For example, in the 2006 research, one learner wanted to understand a land title and learn how it is used in relation to her life; otherwise, she could easily have been a victim of print. She will not have personal agency and that makes understanding text extremely difficult. An adult learner should be able to ask questions of print at the wholetext level, and not just be a passive recipient of that text. The learner needs to identify how texts are used in the world and use this knowledge in their everyday lives.

\section{Extending Literacy into a Sociocultural View}

The social view of literacy is flexible, thus allowing for different dimensions to influence the definition and understanding of the term literacy. The sociocultural view of literacy is not any different, as it embraces diversity in its recognition of individuals and social practices as central to understanding literacy. This section acknowledges the role of the new literacy studies-ethnographic and cross-cultural studies-in shaping the different understandings of literacy/literacies away from a single definition.

\section{New Literacy Studies: Ethnographic and Cross-Cultural Understandings of Literacy}

Ethnographic and cross-cultural research studies view individuals and social practices as central to understanding literacy. Ground-breaking research studies by Cole \& Scribner (1981) of the Vai people of Liberia and Heath (1983) of three communities in the Piedmont region in the southeastern United States documented new understandings of literacy. Cole \& Scribner's study reveals that "literacy is not simply a matter of learning how to read and write a particular script but rather in a much broader sense of being able to apply knowledge for specific purposes in particular contexts of use" (p. 236). Heath's ethnographic study demonstrates that "there is no universality to literacy, there are many literacies. To describe only one set of uses and functions is to miss the myriad other uses and functions among the literacies of communities throughout the world" (cited in Collins \& Blot, 2003, p. 44). I will share three Ugandan examples as a way of demonstrating that the success of literacy learning programs depends on specific purposes and context.

First I will describe the REFLECT approach by Action Aid International, a British development agency operating in Uganda. REFLECT (Regenerated Freirean Literacy 
through Empowering Community Techniques) is a sociocultural approach that relies heavily on community initiative. REFLECT aims "to integrate literacy and numeracy teaching with broader efforts to stimulate development locally and to address communities' social and political concerns" (Barton, 2007, p. 192). REFLECT is a contextualized way of drawing together literacy uses in people's lives aimed at socioeconomic transformation. Uganda is one of three countries (Bangladesh and El Salvador are the other two) in which Action Aid International pioneered the REFLECT approach in the 1990s. Some selected districts in western Uganda were used for the program. The success stories that resulted from implementing REFLECT as a community-empowering tool affirmed the importance of context in literacy promotion activities.

Second is the ABEK approach (Alternative Basic Education for Karamoja), which is designed to adapt to the migratory nature of the Karamojong people. This approach was initiated and implemented in Karamoja region in the northeastern part of Uganda (Nyamugasira, Aanyu \& Robinson, 2005). The Karamoja region is characterized by limited use of reading and writing, or low literacy, and is occupied by the ethnic minority communities of Dodoth, Jie, and the Karamojong, who practice agropastoralism; this region has, since the attainment of Ugandan independence in 1962, been lagging behind the rest of the country in terms of socioeconomic development (Jjuuko, Kwiri \& Okech, 2010). A number of Adult Basic Education programs have been initiated and supported in the Karamoja region to address the problem of poverty by tackling the issue of illiteracy. Also, several development-related NGOs and development partners are operating in the region, supporting a number of literacy and skills development initiatives (Jjuuko et al., 2010).

Finally, there is the implementation of the FAL Program in the Ugandan district of Kalangala by the MGLSD, with assistance from the Icelandic International Development Agency (ICEIDA). Kalangala is a fishing community, and it is hard to reach it for service delivery. The support from ICEIDA was timely, and driven by Iceland's experience with its own fishing communities. In two phases (2002-2005 and 2005-2010), the project aimed to tackle the demographic, geographic and economic challenges of the district by empowering individuals with literacy skills, among others. There are notable successes and lessons learned from this MGLSD/ICEIDA collaboration that are deemed replicable in other parts of the country (Mabuya, Odedo \& Gidudu, 2010) where the government runs the FAL Program. During the 2006 data collection period, a number of adult learners made mention of the Kalangala district experience. They felt inspired by the stories coming out of the FAL Program classes in Kalangala district. These stories were shared through a radio program every Sunday afternoon, to which many of the learners tuned in to listen. The learners went on to express the desire to visit these classes and learn from these "successful" adult learners.

These three examples demonstrate the existence of multiple literacies that are influenced by different sociocultural contexts. These experiences demonstrate the uniqueness that individuals and societies bring to literacy. There are diverse and specific uses of literacy, a complexity that is overlooked by the functional literacy approach. Indeed literacies are learned and sustained in situations of use. The application of literate knowledge to specific contexts demonstrates the role of literacy practices in individual lives, and "whichever forms of reading and writing we learn and use, they are associated 
with social identities, expectations about behaviour and role models" (Maybin, 1994, p. 140).

Ethnographic and cross-cultural studies have grounded the understanding of literacy within the social contexts of individual lives. The individual as a learner has the power to construct meaning, and as a result many literacy scholars have agreed that "approaches to literacy education assume that the meanings of words and texts cannot be separated from the cultural and social practices in which and by which they are constructed" (Rowan, Knobel, Bigum \& Lankshear, 2002, p. 88). Literacy has to be understood and examined within sociocultural contexts taking into account events and practices that influence individual learners' purposes and ways of learning to read, write and communicate. Socially, context and practices influence the definitions and understanding of literacy.

\section{Research Study and Methodology}

The data used in this discussion was collected in 2006 and 2011 respectively as part of two separate qualitative research studies on the Functional Adult Literacy Program in Uganda. In 2006, my research was guided by the three themes of literacy learning, poverty reduction, and empowerment of FAL Program learners. I visited two village literacy classes in the subcounty of Kituntu within the district of Mpigi in central Uganda. Structured interviews were used for data collection from six adult learners and 2 literacy instructors. In 2011, as part of my postdoctoral research into suggesting alternative ways of making literacy learn-ing more sustainable for adult learners in their rural communities, 114 adult learners were selected from three districts of Jinja, Iganga, and Kamuli in eastern Uganda. Questionnaire interviews were used for data collection, and the data was analyzed both qualitatively and quantitatively, although most of the information in this discussion is presented quantitatively.

\section{Results}

\section{1) What are the benefits of being literate?}

The adult learners interviewed in 2006 and 2011 shared the information shown in Chart 1 below.

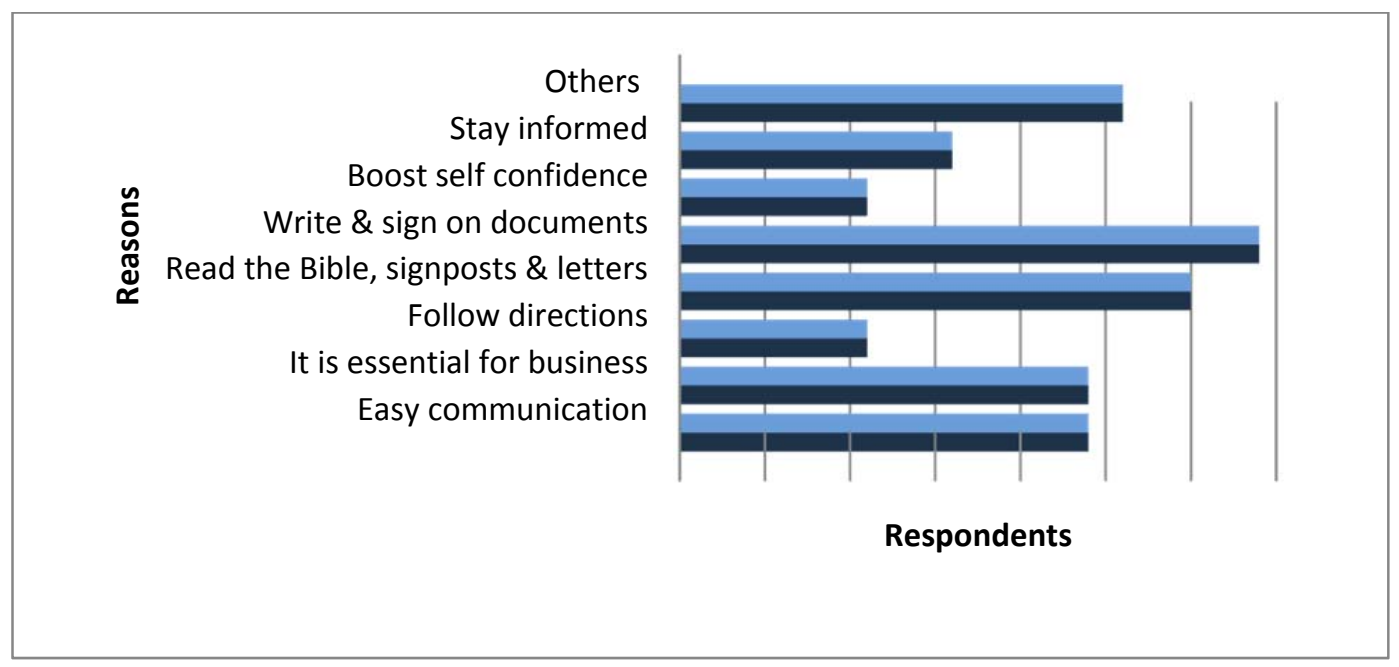

Chart 1: Benefits of literacy 
A majority of respondents indicated the ability to write and sign documents as the first benefit of being literate. This was followed by being able to read either the Bible, for those who are Christians, or signposts and letters. Adult learners also mentioned other benefits which I termed as "others;" these include operating a mobile phone, assisting children with their homework, participating in voting, getting a job, improving sanitation, personal growth, home improvement, banking, and keeping confidential information. Literacy as essential for business and for making communication easier was also mentioned. The power of literacy in learners' lives is clearly identifiable, and it is appreciated as a communicative purpose.

\section{2) What are the reasons for needing literacy skills?}

This question was asked of adult learners in 2011 and their responses are shown in chart 2.

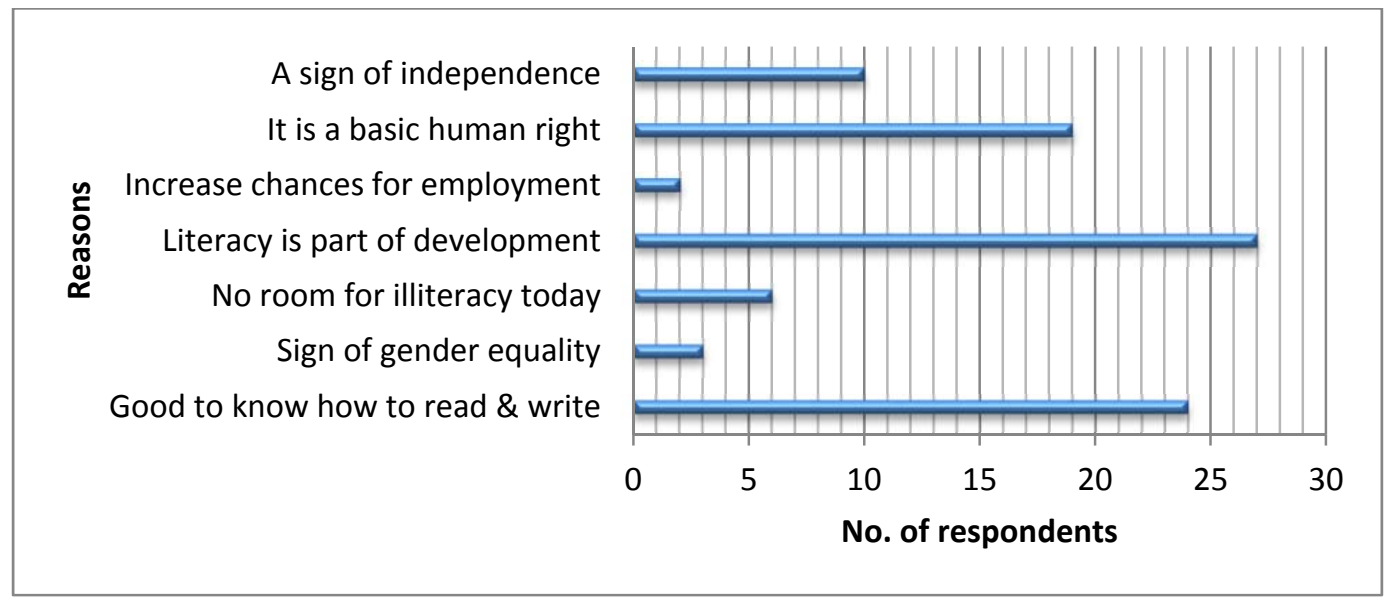

Chart 2: Reasons for needing literacy

In chart 2 above, adult learners' first reason for needing literacy is because literacy is viewed as part of development. This reason is closely followed by the appreciation of the ability to read and write. Literacy as a basic human right as well as a sign of independence were also voiced. Literacy learning is important to these learners, and the value and the different uses that are attached to being literate in society have clearly been shown in chart 2. These reasons are also interlinked and form a justifiable cause to support literacy learning in their communities.

\section{3) What are the positive attributes of the FAL Program?}

The collective examination of adult learner responses from 2006 and 2011 showed that the fight against illiteracy received an overwhelming majority of responses as a positive attribute of the FAL Program, as shown in chart 3 below. 


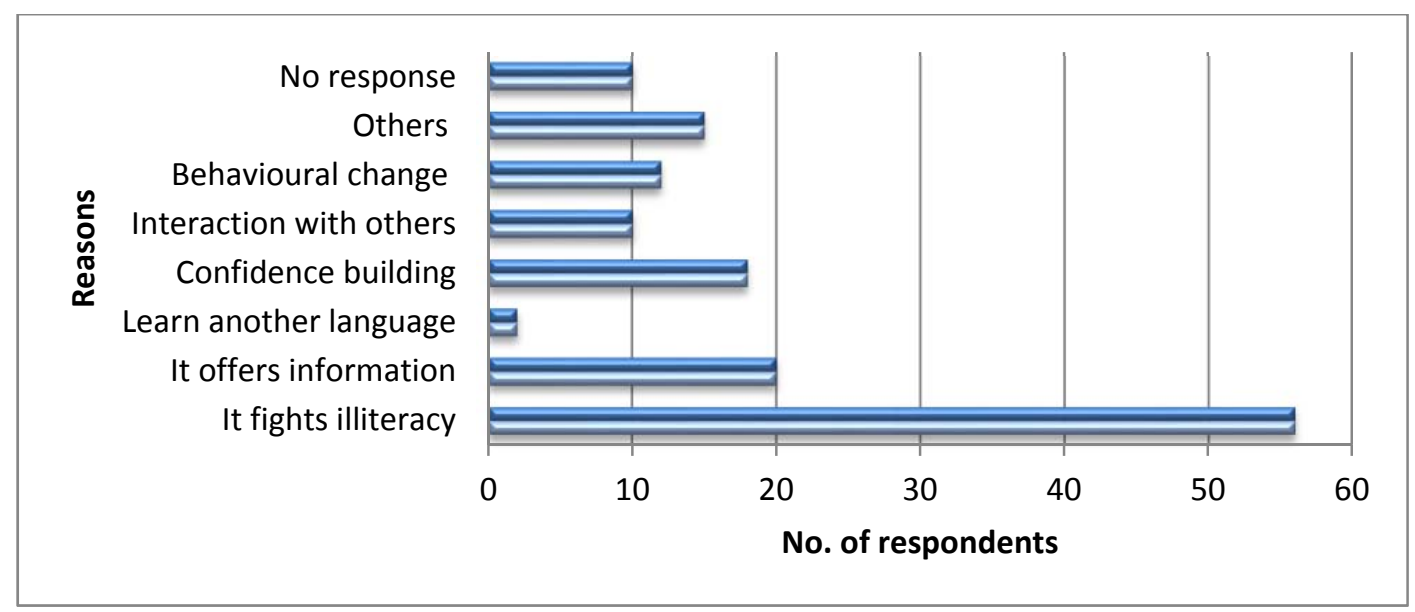

Chart 3: Positive attributes of the literacy program

Also indicated in the chart, the FAL Program offering information and building confidence among adult learners were viewed as the second and third most positive attributes. The fourth and fifth were interacting with other learners and behavioral change. The responses classified as "others" include such reasons as the program being interesting; the program offering free learning; learning relating to everyday life; knowledge on caring for the family is shared; acquisition of better communication skills; drafting of confidential documents; and learning about village banking. In a way, the benefits of literacy and the reasons for needing literacy mentioned earlier may have influenced the adult learners' responses to the question concerning the positive attributes of the FAL Program.

\section{4) What are the negative attributes of the FAL Program?}

Again, adult learners in 2006 and 2011 shared their views, as shown in chart 4. Although more than 40 respondents were of the view that there was nothing wrong with the literacy program, 30 individuals whose responses are classified as "others" mentioned some of the following issues: Walking long distances to class, employment upon completion is not guaranteed, no remuneration for literacy instructors, missing of classes during rainy seasons, learners coming late to class, no opportunity for further training, absenteeism, the program does not address our local problems, and lack of facilitation. 


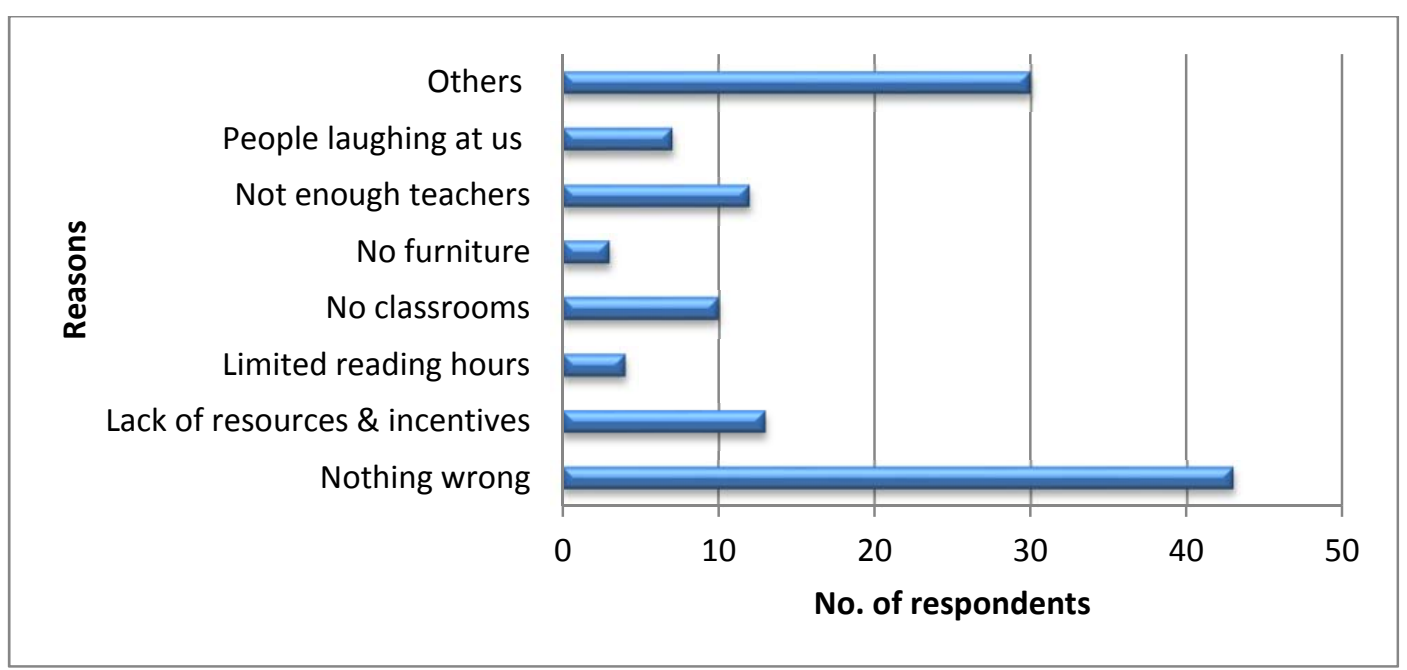

Chart 4: Negative attributes of the program

The other reasons as shown on the chart include lack of resources and incentives, not enough teachers, and no classrooms. Interestingly, this data collected in two different regions of the country and in different years still reflects the same negative attributes shown in chart 4 . The existence of these negative attributes is affecting the literacy program's effectiveness, and is an indication of how challenging it is to run a national literacy program in different regions and districts in the country. Obviously, this program is not fully contextualized to address local community literacy needs. As a result, development organizations have incorporated their own agendas within the existing FAL Program; this is happening in the eastern region but not in the central region. This approach is one way of addressing the negative attributes of the FAL Program and thereby adding value to the local literacy classes.

The challenges to effective program implementation limit the extent to which the program can be a worthwhile and feasible national opportunity for adult literacy learning in Uganda. The promotion of this literacy program should not be about "throughput" numbers, where attention is focused more on the number of learners than the quality of learning outcomes and the long term impact of literacy on the adult learners, their families, and communities. It is not enough for the government to run a national literacy program if it is largely devoid of a social context and local community challenges, as this becomes an unproductive program similar to UNESCO's Experimental World Literacy Program of the years between 1967 and 1974.

\section{5) How can adult illiteracy be addressed in the local communities?}

A majority of respondents recommended the sharing of learner stories with all community members as the first approach to addressing illiteracy. Conducting mobilization exercises and holding village meetings were also mentioned as other approaches that could be used to get more individuals involved in the current literacy program in the community. The local context through which literacy is promoted is essential to developing a productive literacy-learning activity that draws on the social experiences of the adult learners. Literacy is a means to social inclusion and this is central to how learners choose to reflect on its role 
in everyday life. Literacy, if well planned and organized, has the potential to lead to social, political, economic, and environmental transformation, as the implementation of the REFLECT approach by Action Aid has revealed. So how can the different concepts of literacy be drawn together to influence the revision of future implementation of the FAL Program in Uganda? The answer lies in redesigning adult literacy learning under the FAL Program as social practice.

\section{Redesigning FAL Learning as Social Practice}

The length of time that the FAL Program has been operational gives literacy implementers the opportunity to review and reconstruct some aspects of the FAL Program, especially to update the curriculum content to reflect the present situation in the country and take account of global trends. The implementation of the program should go beyond labeling people "literate" or "illiterate". Through redesigning literacy learning as social practice, local communities will have an important part to play in shaping the types of literacy that are meaningful to them. Of paramount importance is the involvement of local communities in forming FAL committees, committed to raising awareness (for example, through community meetings and at religious services) of the contribution of literacy learning to communal growth and development. The MGLSD has a vital role that includes strengthening the collaboration between local communities and other literacy providers.

Critical social theorists have developed their own understanding of literacy as more than functional. Adult literacy learning should be about the interests and needs of the learners. Therefore, literacy learning, when placed within the sociocultural, economic, and political contexts of the lives of adult learners, should allow them to draw on local resources to develop and sustain their literacy interests. The MGLSD should look into a grassroots approach to literacy learning, as a way of beginning to review aspects of the FAL Program that have discouraged adult literacy learners from implementing the acquired knowledge, and also for new learners to join the FAL Program. An adult literacy program designed within a social community-based context has a chance of addressing inequality, inaccessibility, and illiteracy among the population. In the long run, adult learners should be able to develop a voice that projects their concerns and is a sign of personal freedom, as professed by the REFLECT approach.

\section{Implications for Research}

This paper has explored the functional and sociocultural approaches to adult literacy learning in the context of Uganda. Functional literacy is just one approach to offering literacy learning in Uganda. However, there is a need to recognize that individual learners exist within diverse social contexts that are central to understanding literacy and educational learning. A number of research studies on Uganda have focused on the implementation of the FAL Program and the areas that need to be improved for the program to be successful in the various districts in the country. More studies are needed to question the functional approach to adult literacy learning in Uganda, as an answer to the rising levels of illiteracy. These studies should challenge the MGLSD to explore social and sociocultural ways of implementing adult literacy programs. UNESCO's functional approach to literacy has been in existence globally since 1945, but still global illiteracy persists. The 
Education for All initiative requires new and diverse ways of promoting literacy, especially among adults, in order to realize every individual's basic right to literacy.

Adult literacy is a significant global issue that requires more attention. Therefore, the nature of literacy programs and their implementation in developing countries like Uganda should be contextualized. This paper suggests that policy makers and implementers in Uganda need to revise the existing literacy programs and policies so as to make them more responsive to local people's struggles for survival, sustained livelihoods, and better community life. Furthermore, a strong sociopolitical backing for literacy programs is needed in order to allow local people to become engaged in shaping the kind of literacy learning interventions most relevant for their local communities.

\section{References}

Barton, D. (Ed.). (1994). Sustaining local literacies. Clevedon, Eng.: Multilingual Matters.

Barton, D. (2007). Literacy: An introduction to the ecology of written language. Oxford: Blackwell.

Bhola, H. S. (1994). A sourcebook for literacy work: Perspective from the grassroots. Paris: UNESCO.

Blake, B. E., \& Blake, R. W. (2005). Literacy primer. New York: Peter Lang.

Carr-Hill, R. A., Okech, A., Katahoire, R. A., Kakooza, A.R., Ndidde, T., \& Oxenham, J. (2001). Adult literacy programs in Uganda. Human Development, Africa Region. Washington, DC: The World Bank.

Chlebowska, K. (1990). Literacy for rural women in the Third World. Paris: UNESCO.

Christie, F. (1990). Literacy in social processes: Papers from the Inaugural Australian systemic functional linguistics. Deakin University: Centre for Studies of Language in Education.

Cole, M., \& Scribner, S. (1981). The psychology of literacy. Cambridge, MA: Harvard University Press.

Collins, J., \& Blot, R. (2003). Literacy and literacies: Texts, power, and identity. Cambridge, UK: Cambridge University Press.

Freire, P., \& Macedo, D. (1987). Literacy: Reading the word and the world. South Hadley, MA: Bergin and Garvey.

Gillette, A. (1987). The Experimental World Literacy Program: A unique international effort revisited. In R. F. Arnove \& H. J. Graff (Eds.), National literacy campaigns: Historical and comparative perspectives (pp. 197-218). New York: Plenum Press.

Grant, A. (1987). Opportunity to do brilliantly: TAFE and the challenge of adult literacy provision in Australia. Canberra: Australian Government Publishing Service.

Gray, W. S. (1956). The teaching of reading and writing. Paris: UNESCO.

Hamilton, M., Barton, D., \& Ivanic, R. (Eds.). (1994). Worlds of literacy. London: Macmillan. 
Heath, S. B. (1983). Ways with words: Language, life and work in communities and classrooms. Cambridge, Eng.: Cambridge University Press.

Jjuuko, R., Kwiri, T., \& Okech, A. (2010). Skills training and non-formal education for poverty reduction in Karamoja: Needs asssessment report. Kampala: Uganda Adult Education Network \& Compuline Ltd. Retrieved from http://www.ugaaden.ac.ug/dmdocuments/Needs\%20Assessment\%20Study\%20Re port $\% 20$ for $\% 20$ Karamoja $\% 20$ Project $\% 202010 \% 20$ final $\% 20 \mathrm{draft} \% 5 \mathrm{~B} 1 \% 5 \mathrm{D}$.pdf

Kisira, S. (2005). Literacy and Adult Basic Education [LABE] in Uganda. In D. Barton \& U. Papen (Eds.), Linking literacy and numeracy programmes in developing countries and the UK (pp. 67-73). London: National Research and Development Centre for Adult Literacy and Numeracy (NRDC).

Levine, K. (1986). The social context of literacy. London: Routledge; Kegan Paul.

Luke, A. (1988). Functional literacy in the classroom. Australian Journal of Reading, 11(1), 4-10.

Luke, A., \& Freebody, P. (1999). A map of possible practices: Further notes on the four resources model. Practically Primary, 4(2), 5-8.

Mabuya, M., Odedo, R. \& Gidudu, H.E. (2010). Government of Uganda/ICEIDA partnership: External evaluation of ICEIDA support to the implementation of FALP in Kalangala District 2006-2010. Final report June 2011. Kampala: MGLSD \& ICEIDA.

Macdonald, H. (1993). Write me in: Improving women's access to literacy training. Canberra: Australian Government Publishing Service - Women's Bureau Department of Employment, Education and Training.

Mace, J. (1992). Talking about literacy: Principles and practices of adult literacy education. London: Routledge.

Maybin, J. (1994). Language and literacy in social practice. Clevedon, Eng.: The Open University.

Ministry of Gender, Labour and Social Development (MGLSD). (2001). Guidelines on implementation of a Functional Adult Literacy Strategic Investment Plan 2000/1 2006/7. Kampala: Directorate of Gender and Community Development.

Ministry of Gender, Labour and Social Development (MGLSD). (2003a). The Social Development Sector Strategic Investment Plan (SDIP) 2003 - 2008: "Integrating human progress with economic growth for sustainable development". Ministry of Gender, Labour and Social Development. Retrieved from http://www.mglsd.go.ug/index.php?page=Policies

Ministry of Gender, Labour and Social Development (MGLSD). (2003b). Functional Adult Literacy curriculum. Kampala: Ministry of Gender, Labour and Social Development. 
Ministry of Gender, Labour and Social Development (MGLSD). (2008). National report on the development and state of the art of Adult Learning and Education (ALE) in Uganda. (Final draft). Kampala. Retrieved from http://www.unesco.org/fileadmin/MULTIMEDIA/INSTITUTES/UIL/confintea/pdf/ National_Reports/Africa/Africa/Uganda.pdf

Ngatjizeko, B. U. (2005). The National Literacy Programme in Namibia. In D. Barton \& U. Papen (Eds.), Linking literacy and numeracy programmes in developing countries and the UK (pp. 77-81). London: National Research and Development Centre for Adult Literacy and Numeracy (NRDC).

Nyamugasira, W., Aanyu, D.A., \& Robinson, C. (2005). Literacy Adult Basic Education (LABE) Uganda: Report of the final evaluation of "Literacy and Continuing Education in Uganda 2000-2005" and "Family Basic Education in Uganda" 2003-2005 Programmes. Kampala: LABE \& Education Action International.

Okech, A., Carr-Hill, R. A., Katahoire, A. R., Kakooza, A. R., \& Ndidde, T. (1999). Report of evaluation of the functional adult literacy programme in Uganda. Kampala: Ministry of Gender, Labour and Social Development; World Bank Mission in Uganda.

Okech, A. (Ed.). (2004). Adult Education in Uganda: Growth, development, prospects and challenges. Kampala: Fountain Publishers.

Rowan, L., Knobel, M., Bigum, C., \& Lankshear, C. (2002). Boys, literacies and schooling: The dangerous territories of gender-based literacy reform. Buckingham, Eng.: Open University Press.

Street, B. (1984). Literacy in theory and practice. London: Cambridge University Press.

Street, B. V. (Ed.). (1993). Cross-cultural approaches to literacy. New York: Cambridge University Press.

Street, B. (1995). Social literacies: Critical approaches to literacy in development, ethnography and education. London: Longman.

Street, B. (1996). "Literacy and power". Open letter - literacy and numeracy studies, 6(2).

Suda, L. (2001). Policies and pedagogies for lifelong literacy: international perspectives for the 21st century. Melbourne: ALNARC.

Taylor, D., \& Dorsey-Gaines, C. (1988). Growing up literate. Portsmouth, NH: Heinemann Educational Books.

Taylor, D. (1997). Many families, many literacies. Portsmouth, NH: Heinemann.

United Nations Education, Science \& Cultural Organization (UNESCO). (1970). Functional literacy: Why and how. Paris: UNESCO.

United Nations Education, Science \& Cultural Organization (UNESCO). (2010). Education For All global monitoring report: Reaching the marginalized - Summary. Paris: UNESCO. Retrieved from http://unesdoc.unesco.org/images/0018/001866/186606E.pdf 
United Nations Education, Science \& Cultural Organization (UNESCO). (2011). Education For All global monitoring report: The hidden crisis: Armed conflict and education. Paris: UNESCO. Retrieved from http://www.unesco.org/new/fileadmin/MULTIMEDIA/HQ/ED/pdf/gmr2011part1-ch1.pdf

Uganda Population Secretariat. (2011). State of Uganda Population Report 2008: Theme: "Population and reproductive health: Broadening opportunities for development." Kampala: Republic of Uganda; UNFPA Uganda. Retrieved from http://www.popsec.org/publications 4 71363301.pdf 